\title{
Studies of field emission process influence on changes in CNT films with different CNT superficial density
}

\author{
IzABela StęPińska $^{1, *}$, Elżbieta CZerwosz ${ }^{1}$, MirosŁaw KozŁowski ${ }^{1}$, Halina WronkA ${ }^{1}$, \\ PIOTR DŁUŻEWSKI ${ }^{2}$ \\ ${ }^{1}$ Tele and Radio Research Institute, Ratuszowa 11, 03-450 Warsaw, Poland \\ ${ }^{2}$ Institute of Physics PASc., Al. Lotników 32/46, 02-668 Warsaw, Poland
}

\begin{abstract}
Field emission from materials at high electric fields can be associated with unfavorable or even destructive effect on the surface of the investigated cathode. The impact of high voltage electric power supply causes locally very strong electric fields focusing on the cathode surface. It causes a number of phenomena, which can adversely affect the morphology and the structure of the cathode material. Such a phenomenon is, for example, peeling of an emissive layer from the substrate or its burnout. It results in tearing of the layer and a decrease or loss of its ability to electrons emission. The cold cathodes in a form of CNT films with various CNTs superficial distribution are obtained by physical vapor deposition followed by chemical vapor deposition. CNTs are catalyzed in pyrolytic process with xylene (CVD), by Ni in a form of nanograins (few nm in size) placed in carbonaceous matrix. These films are built of emissive CNTs - carbonaceous film deposited on different substrates. In this work, the morphology and topography of superficial changes resulting from external electric field in such films were investigated.
\end{abstract}

Keywords: field emission; carbon nanotubes; CVD

\section{Introduction}

Recently, research on field emission from carbon nanotubes (CNTs) [1-4] has confirmed the efficiency and stability of electron emission and a long lifetime of emission of these materials. CNTs exhibit low threshold electrical field value that is associated with their high aspect ratio, 'whisker-like' shape, which provides the optimum geometrical field enhancement. For CNTs the aspect ratio amounts to $\sim 1000$ [5]. Generally, CNTs films are used as cold cathodes in various electronic devices which need electron sources. Such emitters should be stable and have a long lifetime. CNTs can be used as electron emitters in two different ways, as single or multiple field emitters. The first ones can be applied in electron microscopy where a single nanotube is used as a field emitter $[6,7]$ due to its small emission area which gives highly coherent electron beam. Possible use for multiple field emitters, which are built from continuous or

*E-mail: izabela.stepinska@itr.org.pl patterned carbon nanotubes films, is field emission display (FED) [8] but it has not been in commercial usage yet.

The failure of nanotube emitters is observed for single emitters as well as for emitter arrays. The phenomena leading to the degradation of the emitters are not completely understood at present, and it seems that several factors play there a role. Firstly, electrostatic deflection or mechanical stresses can cause alterations in the shape and/or surroundings of the emitter, which may lead to a decrease in the local field amplification. Secondly, high current can rapidly damage the nanotube [9-12]. In [13], authors have studied the failure of multiwall carbon nanotubes field emitters grown by CVD on planar substrates during field emission. The failures induced by high currents led to splitting of the tube near its center, which is consistent with local evaporation caused by resistive heating. The failure occurred near the contact during field emission from CVD films, which suggests a degradation mechanism that is due either by mechanical failure caused 
by tensile loading of the emitter under the applied electric field or by resistive heating at the contact that was enhanced by the mechanical stress.

Most popular applications of carbon nanotubes films used as electron sources are electron tubes such as luminescent lamps, X-ray [14, 15] and microwave tubes [16]. Bonard et al. [17] developed a cathodoluminescent light-emitting element of cylindrical geometry. The cathode in a form of a metal rod with deposited CNTs was located on the axis of a glass tube covered by phosphor from the inside. CNT light-emitting elements of various colors in the form of a filamentary electric lamp were proposed by Saito et al. [18].

In this paper, we present the cold emitters that are applied in a new type of lighting. These emitters are based on multiwall carbon nanotubes films. The field emitter is a carbon nanotube film (CNTs film) deposited on metallic substrate in two-step method PVD/CVD. The details of emitters preparation, properties and lamp construction were published in our previous papers [19-22]. The quality of the emitter, its stability, working time, efficiency are important factors for lighting properties of lamps with such emitters. Here, we discuss the changes in superficial layer of emitters induced by electric field, electrostatic reaction and temperature effects connected to effects experienced during emission.

\section{Experimental}

The carbon nanotubes films were obtained by two-step method originally elaborated in Tele and Radio Research Institute. This method consists of two stages. The first stage is physical vapor deposition (PVD) wherein nanocomposite films are obtained. The precursors of these films are $\mathrm{C}_{60}$ and nickel acetate $\left(\mathrm{CH}_{3} \mathrm{COO}\right)_{2} \mathrm{Ni}$. Both compounds are evaporated from two separate sources in a vacuum chamber at the dynamic pressure of $10^{-3} \mathrm{~Pa}$. The carbon-nickel (C-Ni) films composed of a carbonaceous matrix and a few nanometers nickel nanograins in it are obtained.

The second step is a modification of the C-Ni films by catalytic pyrolysis of xylene $\left(\mathrm{C}_{8} \mathrm{H}_{10}\right)$ in chemical vapor deposition (CVD) process. Such additional carbon source is required for carbon nanotubes growth. Ni nanoparticles obtained in PVD process act as catalyst for the carbon nanotubes growth.

The CVD process is carried out under dynamic conditions in the argon and xylene flow in a quartz tube. In a heating zone of the oven, at high temperature, decomposition of the hydrocarbon and chemical reaction on the substrate take place. $\mathrm{Ni}$ in a form of small nanoparticles, obtained during the PVD process at high temperature, agglomerates into larger grains which migrate to the surface of the film and stimulate the growth of the nanotubes. The mechanism of CNTs growth occurring in this method, so-called 'tip growth' mechanism, has been described in [23]. CNTs films, prepared in this way, are composed of a carbonaceous matrix which contains CNTs with Ni nanoparticles.

The scanning electron microscopy and transmission electron microscopy were used to identify the structure, morphology and topography of investigated samples. SEM studies applying secondary and backscattered electrons were performed with JEOL JSM-7600F field emission scanning electron microscope operating at $5 \mathrm{keV}$ incident energy. The topography of the film surfaces were imaged using a secondary electron (SE) detector. A low-angle backscattered electron (LABE) detector was used to define the morphology of the samples by observing changes in their contrast composition. The contrast depends on the atomic number of elements of an observed microstructure. Areas with a higher atomic number are brighter, while those with a lower atomic number are darker. The Titan Cubed transmission electron microscope operating at $300 \mathrm{kV}$ accelerating voltage was used for the CNTs films structure investigations.

The field emission measurements were carried out on a special experimental setup presented in Fig. 1.

In the experimental vacuum chamber two electrodes are placed in the diode configuration: anode and cathode. The cathode is the studied film sample and anode is a metal spherical surface. 


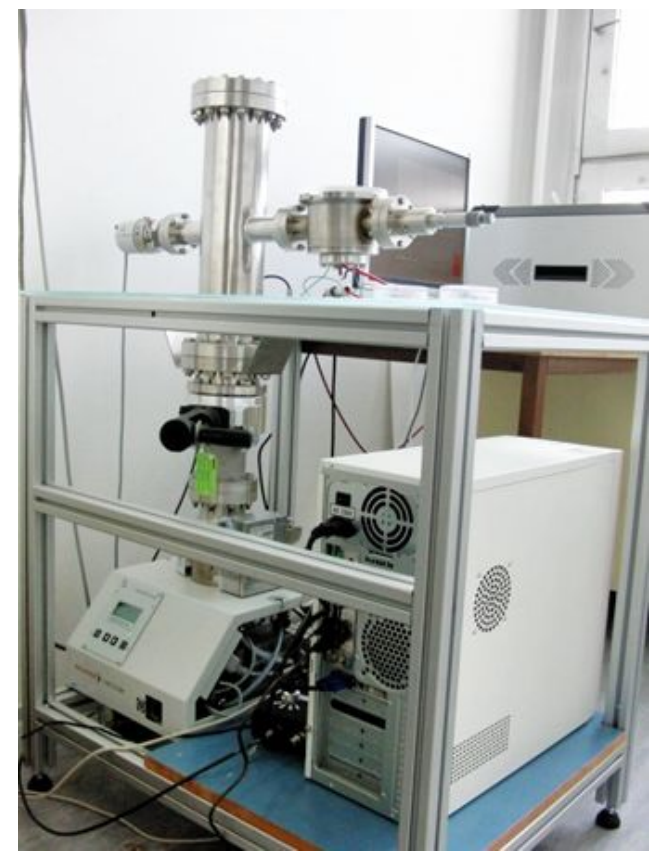

Fig. 1. The experimental chamber setup for FE measurements. This experimental setup is equipped with vacuum pump; vacuum vessel; experimental vacuum chamber; vacuum measuring head; high voltage supply; computer for data acquisition and analysis.

The measurements were carried out with a supply power voltage $\mathrm{U}$ changing from $0 \mathrm{kV}$ to $3.8 \mathrm{kV}$. The distance $\mathrm{d}$ between cathode and anode was changed from $100 \mu \mathrm{m}$ to $1000 \mu \mathrm{m}$. We assumed the electric field intensity $\mathrm{E}$ as uniform and defined as $\mathrm{U} / \mathrm{d}$.

\section{Results and discussion}

The initial nanocomposite films were deposited on various substrates such as Si plates, Mo, steel or Si with transition layers (Ti). In Fig. 2, SEM images of nanocomposite films obtained by PVD method on different substrates are presented. Depending on substrate and technological parameters of PVD process, different factures of C-Ni films were observed. Some of the films have angular carbonnickel grains on the surface and others, fine-grained facture. It is also connected with $\mathrm{Ni}$ content [24].

Due to CVD modification, the CNTs films with various CNTs distributions on surface have been obtained. In Fig. 3, SEM images for three types of

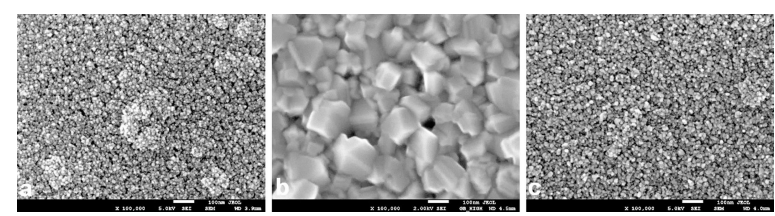

Fig. 2. Nanocomposite films obtained by PVD method on different substrates (a) steel, (b) Si, (c) Mo.

CNTs films are presented. Such films were tested as electron emitter. The films containing individual CNTs used at a large distance between them did not exhibit field emission or emissive properties or they were very weak. The films with high and low distribution density of CNTs on the substrate surface had different emissive properties. However, the films with CNTs rarely distributed on the surface exhibited a stronger and a stable electron emission than the films with high density of CNTs. Fig. 4. shows an example of I-E characteristics of such films.

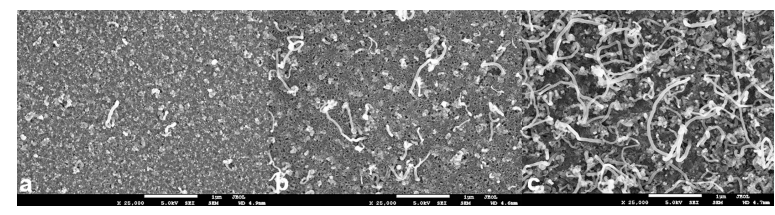

Fig. 3. (a) individual CNTs films, (b) low density CNTs films, (c) high density CNTs films.

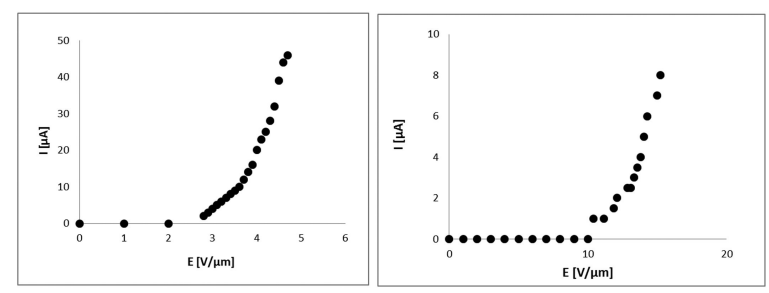

Fig. 4. I-E characteristics of (a) low density CNTs films, (b) high density CNTs films.

The CNTs film which exhibited the field emission was used in an optical setup where the electron emission was visualized on the luminescent screen covered by phosphor. The fluctuations of emission current intensity were observed for some samples. In the luminescent screen these fluctuations are visible as appearing luminous spots with varying intensity (Fig. 5). This phenomenon occurred with 
different intensities and frequencies. The flickers of light may be connected to the character of the CNTs films and inhomogeneous surface. It is possible that longer CNTs need much lower electric fields for electron emission than the short ones. Also the destructive effects induced in superficial layers by field emission should be considered.

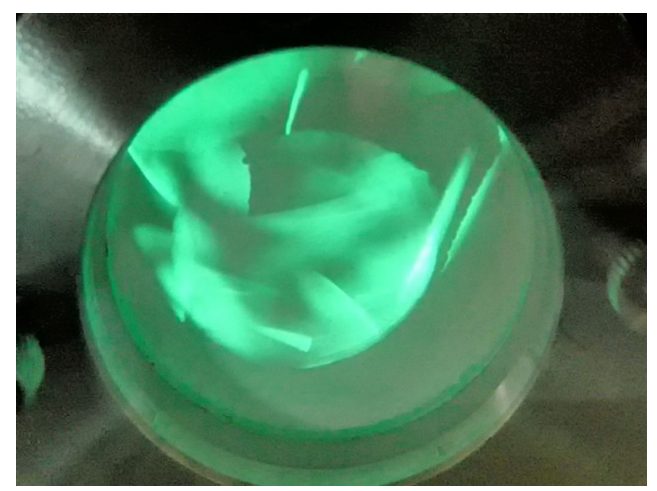

Fig. 5. Images from the screen during field emission from CNTs films at $1.5 \mathrm{kV}$.

The changes in superficial layer of CNT films caused by field emission phenomenon can be in various forms. For example, peeling of the emissive layer from the substrate or the burnout and degradation of the surface can be observed.

\subsection{The influence of strong electric field on changes in emitters}

When high voltage (above $19 \mathrm{~V} / \mu \mathrm{m}$ ) is supplied to obtain field emission from CNT film, it is connected to a superficial destruction of the film. This effect is based on tearing out a fragment of emissive layer and changes its morphology and topography.

In Fig. 6 CNTs films before and after emission experiment are shown. The area of detached fragment of the film is presented in various magnifications. This film was deposited on $\mathrm{Si}$ substrate with Ti transition layer. The films surface was characterized by presence of individual carbon nanotubes distributed in a large distance between them. This type of emitter requires very high supply voltage. In this case, field emission measurements were performed under high electric fields with maximum value of $25 \mathrm{~V} / \mu \mathrm{m}$. In the SEM images point breaches, in the form of microcraters, can be found. There are tens of such craters with different diameters in the area of observation. The edges of the craters are very rugged and in their center, melted film fragments are visible.
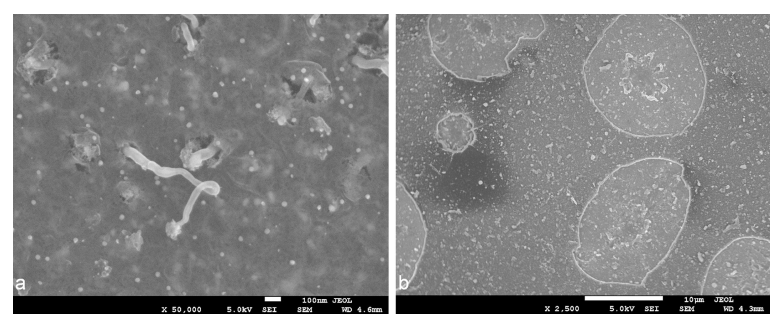

Fig. 6. CNTs films on Si/Ti plate before (a) and after (b) field emission measurements.

Fig. 7 presents the surface of the film deposited on Mo foil. In Fig. 7a a homogeneous film with high density distribution of CNTs, before field emission measurements is presented. This film does not exhibit emissive properties. After emissive investigations (Fig. 7b) it was found that Mo foil is covered only partially with CNTs films. There is a high probability that pulling out the film fragments is connected to the action of a strong electric field.

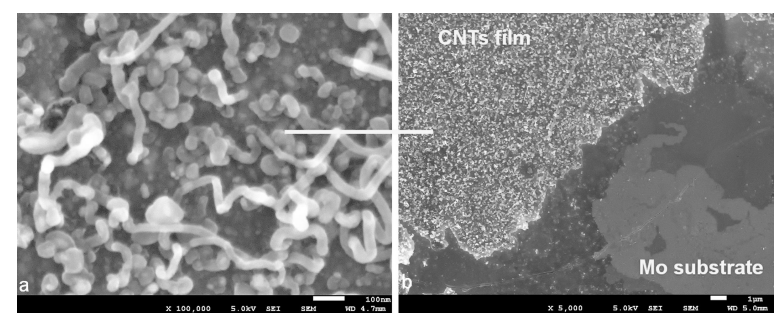

Fig. 7. CNTs films on Mo foil before (a) and after (b) field emission measurements.

\subsection{The influence of high temperature within short circuit field}

Very strong local electric field generates locally high temperature. Especially within the field of short-circuit or an avalanche breakdown, the gradients of temperature occur, which cause changes in structure, morphology and topography of CNTs films and local chemical composition. An example of the influence of high temperature on a CNTs film obtained on steel $(1 \mathrm{H} 19 \mathrm{NT})$ is presented in 
Fig. 8. The sample was studied by SEM and TEM before and after emission experiment using the optical setup. The change of film structure appeared as brighter spots on the darker background film. Fig. 8a shows SEM images of CNTs film before emissive measurements in secondary (SE) and backscattered (BSE) electron modes. The small $\mathrm{Ni}$ nanoparticles densely distributed in carbon matrix are found. Also individual CNTs are observed on the surface. In BSE mode, Ni nanoparticles are clearly visible as bright objects and the carbonaceous matrix as a dark area. However, the studies of the brighter spots which appeared after FE investigations revealed the changes in morphology and structure of the film. New nanostructural objects were found. They had spherical shapes and diameters up to $100 \mathrm{~nm}$. To identify them the transmission electron microscopy was used.

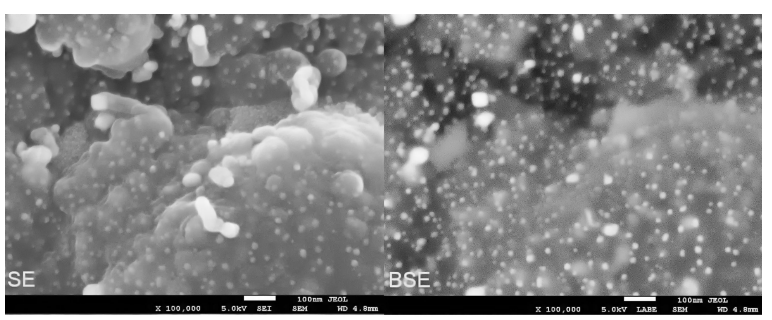

(a)

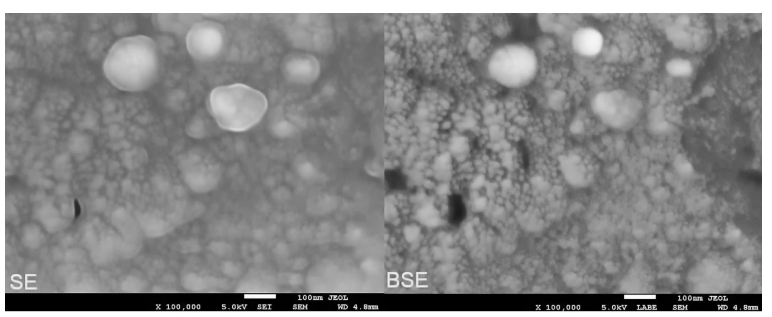

(b)

Fig. 8. CNTs films on steel before (a) and after (b) field emission measurements.

In Fig. 9, a fragment of microstructure from the area where a corresponding electrical breakdown appeared and EDS spectrum from this area are presented. EDS spectrum contains the peaks from carbon and nickel (films ingredients) and it clearly shows additional peaks from iron and chromium. This means that when the avalanche breakdown occurred then local melting of the substrate took place and therefore, in EDS spectrum. additional peaks can be seen. These peaks are connected to additional elements originating from the substrate. Observations and investigations were also made in the scanning transmission mode (STEM) - Fig. 9a. The diffraction patterns of a random area of the shell (right side) and of an area within the circle (Fig. 9c) were also made. The areas differ significantly - the left side shows diffraction pattern from the phase rich in $\mathrm{Cr}$ and $\mathrm{Fe}$ as well as nickel, carbon and oxygen. Measured interplanar spacing may indicate oxides of nickel, iron and chromium, however, a precise identification of phases at this stage is very difficult. EDS method allows a precise analysis of individual nanoparticles including particles of regular spherical shape rich in $\mathrm{Cr}$ and, to a lesser extent, Fe, Ni and C (Fig. 9d).

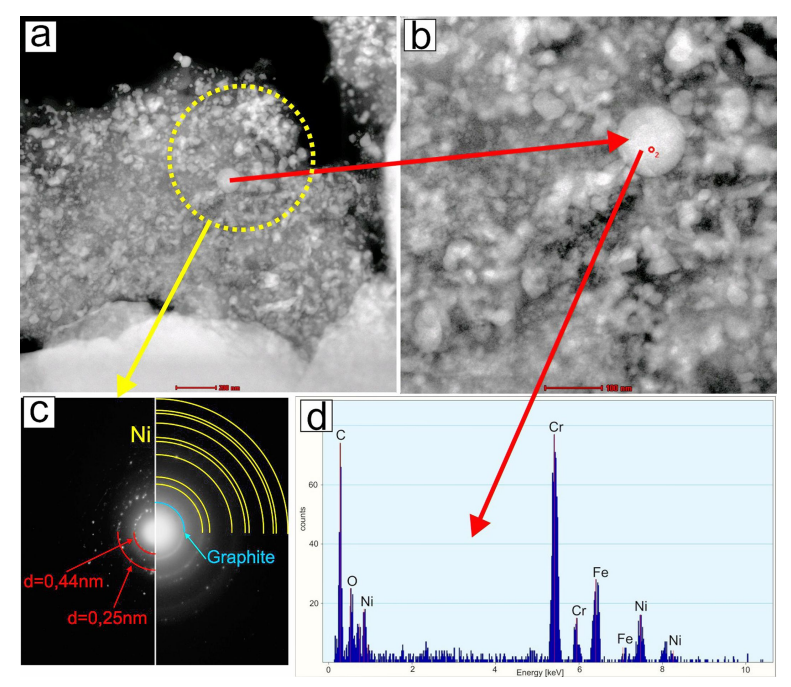

Fig. 9. (a) STEM image of the film, (b) the spherical particle, (c) electronogram from the area within the circle in Fig. 9a, (d) EDS spectrum of the nanoparticles marked in Fig. 9b

The influence of high temperature which is generated by strong local electric field is also visible in nanometric scale. SEM images of CNTs (Fig. 10) before and after field emission prove that the morphology and topography of the CNTs were changed as a result of interaction between electric field and CNTs emitters. SEM investigations were performed in the same conditions in both cases. CNTs after field emission studies (Fig. 10b) are wider and they are surrounded by some deposit, that is probably an amorphous carbonaceous shell. It occurred 
due to melting of CNT surface. This films contained CNTs densely distributed on the surface and field emission was obtained at high electric fields of $19 \mathrm{~V} / \mu \mathrm{m}$.
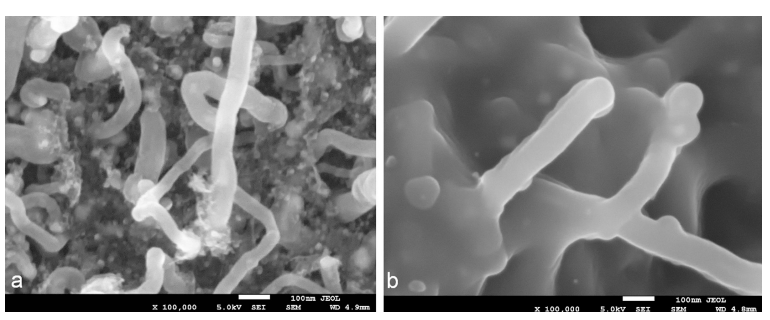

Fig. 10. CNTs emitters before (a) and after (b) field emission measurements.

\section{Conclusions}

CNTs films prepared by two-step method have been used as electron emitters in cold cathodes. Depending on the technological parameters, various films were obtained. Most of them exhibit field emission phenomenon. FE occurs at electric fields relevant to the emitter. At strong electric fields (more than $19 \mathrm{~V} / \mu \mathrm{m}$ ) a superficial changes in morphology, topography and structure of the CNTs films take place. These changes are associated with:

1. Pulling out the film fragments by the action of a strong electric field.

2. Changes in topography and morphology of the film/emitter.

3. The formation of new structural objects due to heat connected to electrical short circuit.

These effects cause destruction in CNTs films and make them useless. Our investigation has also shown that there are optimal emissive films and these are the films with rarely distributed CNTs in carbonaceous matrix. Such films exhibit field emission at a very low electric fields $(1 \mathrm{~V} / \mu \mathrm{m}$ to $7 \mathrm{~V} / \mu \mathrm{m})$ and do not reveal any superficial changes.

\section{Acknowledgements}

This work was supported by the Applied Research Programme of the National Centre for Research and Development
No. PBS1/A5/16/2012 named "Light sources with cold emitter" and the Ministry of Science and Higher Education under the Research Project "Nanocomposite C-Ni-Pd films for opto- and bioelectronics applications".

\section{References}

[1] Groning P., Ruffieux P., Schlapbach L., GronING O., Adv. Eng. Mater., 5 (2003), 541.

[2] Bonard J.M., Croci M., Arfaoui I., Noury O., Sarangi D., Chatelain A., Diam. Relat. Mater., 11 (2002), 763.

[3] Nilsson L., Groening O., Emmenegger C., Kuettel O., Schaller E., Schlapbach L., Kind H., Bonard J-M., Kern K., Appl. Phys. Lett., 76 (15) (2000), 2071.

[4] Wanga X.Q., Wanga M., Lib Z.H., Xua Y.B., He P.M., Ultramicroscopy, 102 (2005), 181.

[5] Filip V., Nicolaescu D., Tanemura M., OKUYAMA F., Ultramicroscopy, 89 (2001), 39.

[6] Jonge N., DRUTEN N.J., Ultramicroscopy, 95 (2003), 85.

[7] Nakahara H.et Al., Appl. Surf. Sci., 256 (2009), 1214.

[8] Wang Q. H. ET Al., Appl. Phys. Lett., 72 (22) (1998), 2912.

[9] Jonge J., Bonard J.M., Phil. Trans. R. Soc. London A, 362 (2004), 2239.

[10] Wang Z.L., Poncharal P., DE $\underline{\text { He}}$ E- W.A., Appl. Phys. Lett., 80 (2002), 856.

[11] Wei Y.Y., Dean K.A., Coll B.F., Jaskie J.E., Appl. Phys. Lett., 79 (2001), 4527.

[12] Wang Q.H., Yan M., Chang R. P.H., Appl. Phys. Lett., 78 (2001), 1294.

[13] Bonard J.M., Klinke C.K., Dean K., Coll B., Phys Rev. B, 67 (2003), 115406.

[14] Yue G.Z. ET AL., Appl. Phys. Lett., 81 (2) (2002), 355.

[15] SarraZIN P. ET AL., Adv X ray Anal., 47 (2004), 232.

[16] READ M.E., 2001 Particle Accelerator Conference, (2001), 1026.

[17] Bonard, J.M.; Kind, H., StÖckli, T.H. ET AL., Solid State Electronics, 45 (2001), 893.

[18] Saito Y., Uemura S., Hamaguchi K., Jpn J. Appl. Phys., 37 (1998) L346.

[19] Czerwosz E., Biernacki K., Stęińska I., RYMARCZYK J., RZEPKA E., WASzUK S., WódKa T., Wronka H., Cold cathode lighting, in: CzERWOsz E. (Ed.), Vacuum Technique \& Technology, Monographs of Tele \& Radio Research Institute, Warsaw, 2014, p. 169.

[20] KozŁowski M., StęPińsKa I., SobCZAK K., CZERWosz E., Proc. SPIE, 9662 (2015), 96624G-1.

[21] StęPińska I., KozŁowski M., Radomska J., Wronka H., Czerwosz E., Mater. Sci.-Poland, 33 (1) (2015), 36.

[22] Stępińska I., Czerwosz E., Wronka H., KozŁowsKi M., Proc. SPIE, 8008 (2011), 800820-1.

[23] StęPińska I., KozŁowski M., SobCZAK K., Elektronika, 8 (2012), 98. 
[24] Czerwosz E., Iwanejko I., Kaminska A., RyMARCZYK J., KeCZKOWSKA J., SUChANSKA M., Craciunoiu F., Comanescu F., IEEE CAS 2010 Proc. (International Semiconductor Conference), 1

Received 2017-01-09 (2010), 91.

Accepted 2018-01-12 